\title{
The Effects of Process Conditions on Improvement of the Compressive Strengths of Reticulated Porous Zirconia
}

\author{
Sujin Lee ${ }^{1,2}$, Chae-Young Lee ${ }^{1}$, Jang-Hoon Ha ${ }^{1, *}$, Jongman Lee ${ }^{1}{ }^{(\mathbb{D}}$, In-Hyuck Song ${ }^{1} \mathbb{D}$ and Se-Hun Kwon ${ }^{2, *(\mathbb{D})}$ \\ 1 Powder and Ceramics Division, Korea Institute of Materials Science, 797 Changwondaero, Seongsan-gu, \\ Changwon 51508, Korea; adsj1503@kims.re.kr (S.L.); cy916@kims.re.kr (C.-Y.L.); jmlee@kims.re.kr (J.L.); \\ sih1654@kims.re.kr (I.-H.S.) \\ 2 School of Materials Science and Engineering, Pusan National University, 2 Busandaehak-ro 63beon-gil, \\ Geumjeong-gu, Busan 46241, Korea \\ * Correspondence: hjhoon@kims.re.kr (J.-H.H.); sehun@pusan.ac.kr (S.-H.K.)
}

check for updates

Citation: Lee, S.; Lee, C.-Y.; Ha, J.-H.; Lee, J.; Song, I.-H.; Kwon, S.-H. The Effects of Process Conditions on Improvement of the Compressive Strengths of Reticulated Porous Zirconia. Appl. Sci. 2022, 12, 1591. https://doi.org/10.3390/ app12031591

Received: 20 January 2022

Accepted: 30 January 2022

Published: 2 February 2022

Publisher's Note: MDPI stays neutral with regard to jurisdictional claims in published maps and institutional affiliations.

Copyright: (C) 2022 by the authors. Licensee MDPI, Basel, Switzerland. This article is an open access article distributed under the terms and conditions of the Creative Commons Attribution (CC BY) license (https:// creativecommons.org/licenses/by/ $4.0 /)$.
Featured Application: Molten metal filter and ceramic membrane.

\begin{abstract}
In recent years, there has been growing interest in porous ceramics in many research areas given their superior thermal and chemical resistance capabilities, unlike porous metals and porous polymers. Among the various types of porous ceramics, reticulated porous ceramics can offer significant industrial potential due to the low density and high permeability of these materials. However, industrial applications are somewhat rare owing to the rather low compressive strength of reticulated porous ceramics compared to other types of porous ceramics. Although there have been many studies related to reticulated porous ceramics, few have focused on reticulated porous zirconia. Therefore, the aim of this study is to determine how to obtain a high compressive strength in reticulated porous zirconia by optimizing the process conditions of the solid loading level and the particle size and by using additives in a zirconia slurry sample. Furthermore, the authors assess the effects on the microstructure and compressive strength of multiple slurry coating, specifically from one to three. In conclusion, the effect of varying these various process conditions on the resulting improvement in compression strength was investigated, and the compression strength of reticulated porous zirconia was significantly increased from 0.14 to $9.43 \mathrm{MPa}$. The characteristics investigated include the pore characteristics (pore density, pore size and pore structure), the sintering behavior (linear shrinkage), the mechanical properties (compressive strength), and the dielectric properties (dielectric breakdown strength).
\end{abstract}

Keywords: reticulated porous zirconia; compressive strength; dielectric breakdown strength

\section{Introduction}

Recently, research on porous ceramics, which possess excellent thermal and chemical resistance as a substitute material for porous metals and porous polymers in harsh environments, has drawn much attention [1-3]. There are many ways to manufacture porous ceramics, such as partial sintering [4], the replica method [5], using a sacrificial template [6], and direct foaming [7]. Among them, the replica method can create a cellular structure containing open pores with a high porosity (70-95\%). The replica method proceeds as follows. A sacrificial polymer template (generally polyurethane foam) is impregnated with a prepared ceramic slurry material, with the extra ceramic slurry squeezed out. After the removal of the excessive slurry and a drying step, the polymer template is burned out and the ceramic material is then sintered [5]. Reticulated porous ceramic materials are commonly applied in heat exchangers [8], for porous media combustion [9], and as a catalyst support [10] owing to their high permeability and superior resistance to different thermal and chemical conditions. Moreover, many researchers have sought to expand the 
applications of these materials, such as to advanced separation/filtration and dielectric materials that utilize reticulated porous ceramics.

Zirconia is known as a typical ceramic material with relatively high mechanical strength and toughness, low thermal conductivity, and superior chemical and erosion resistance [11]. It is used in various industrial applications as an electronic and structural material. Moreover, zirconia with a porous structure has been applied to the biomedical field, with examples being bone scaffolding and implants due to its excellent biocompatibility [12]. Pure zirconia undergoes a phase transformation from monoclinic at room temperature to tetragonal at about $1173{ }^{\circ} \mathrm{C}$, and then to cubic at approximately $2370{ }^{\circ} \mathrm{C}$. During the phase transformation, there is a volume variation (about $5 \%$ ) from tetragonal to monoclinic, which degrades the characteristics of this material. Therefore, pure zirconia requires the addition of a stabilizer oxide, leading to stabilized zirconia at room temperature. Stabilized zirconia can be prepared by adding various types of stabilizers $\left(\mathrm{Y}_{2} \mathrm{O}_{3}\right.$, $\mathrm{MgO}, \mathrm{CaO}$, and $\mathrm{CeO}$ ). A common type is $3-5 \mathrm{~mol} \%$ yttria-stabilized zirconia. In particular, $3 \mathrm{~mol} \%$ yttria-stabilized zirconia is the most thermally stable type with the best tensile strength [13].

Porous zirconia is mainly manufactured by means of the sacrificial template method [6] and by direct forming [7]. When manufacturing porous zirconia using the sacrificial template method, it is difficult to control the pore characteristics, specifically the porosity, pore size, and pore structure, due to the uneven mixing of the pore-forming agents. When preparing porous zirconia using the direct forming method, the resulting closed pore structure limits applications that require an open pore structure. On the other hand, when seeking to produce porous zirconia with a cellular structure, the replica method is the only method that can be used [14]. However, one drawback of the replica method is the insufficient compressive strength resulting from the removal of the polymer template corresponding to the strut after a heat treatment compared to other methods (i.e., the direct forming and sacrificial template methods). Additionally, cracks can easily occur due to shrinkage arising during the sintering process. Therefore, this paper focuses on the manufacturing of a completely reticulated type of porous zirconia with excellent compressive strength by tailoring the process conditions. First, we optimize the viscosity of the zirconia slurry by tailoring the solid loading level, the particle size and the type of binder and dispersant used, as the viscosity of the ceramic slurry influences the coating state, where cracks, voids, and defects should be minimized. Second, we utilize multiple slurry coatings, increasing the number of coatings from one to three. It is clear that excellent specimens can be obtained from multiple slurry coatings, which will help to improve the compressive strength. Thus, it is timely that this work is carried out to examine the effects of multiple slurry coatings.

\section{Materials and Methods}

Zirconia was used in the form of a commercial powder $(<0.5 \mu \mathrm{m}$, HWYA-2, Guang Dong Huawang, China) that was stabilized with $3 \mathrm{~mol} \%$ yttria. The zirconia powder samples were ball-milled for $0,1,4,8$, and $24 \mathrm{~h}$ using zirconia balls $5 \mathrm{~mm}$ in size.

The average particle size of the zirconia was controlled by ball-milling using zirconia balls (ball size: $5 \mathrm{~mm}$ ) for $0,1,4,8,24 \mathrm{~h}$. A batch of zirconia slurry consists of $100 \mathrm{~g}$ of zirconia, $100 \mathrm{~mL}$ of distilled water as a solvent, $0-1.5 \mathrm{wt} . \%$ of polyvinyl alcohol (PVA) as an organic binder (PVA 500, Junsei Chemical, Tokyo, Japan) and 0-1.5 wt.\% of Dolapix CE64 as a dispersant (Zschimmer \& Schwarz Chemie GmbH, Lahnstein, Germany). Each component was placed in a plastic bottle with zirconia balls to undertake the ball-milling process. A mass ratio of 1:2 for the powder and balls was always maintained. In order to coat the prepared zirconia slurry uniformly on the polyurethane foam with pores per inch (PPI) values of 25, 45, 60, and 80 , it was impregnated into the zirconia slurry and the samples were pressed to remove any remaining slurry.

The prepared specimens were then dried at $80{ }^{\circ} \mathrm{C}$ for $24 \mathrm{~h}$ in an oven. After the drying step, each specimen was heat-treated at $400^{\circ} \mathrm{C}$ for $1 \mathrm{~h}$ to burn the polyurethane 
foam and was then sintered at $1480{ }^{\circ} \mathrm{C}$ for $1 \mathrm{~h}$ at a rate of $3{ }^{\circ} \mathrm{C} / \mathrm{min}$ in a controlledatmosphere furnace. The densities of the zirconia specimens were measured according to the weight-to-volume ratio. The pore characteristics were characterized by mercury porosimetry (AutoPore IV 9510, Micromeritics, Norcross, GA, USA). The geometry was assessed and macrostructure analysis was conducted with an optical camera, and the microstructures were observed using scanning electron microscopy (SEM, JSM-5800, JEOL, Tokyo, Japan). Micro-CT was utilized to observe the skeleton microstructure. Image reconstruction was performed with tomographic reconstruction software (VG Studio Max 3.0). The viscosity was measured using a rotational rheometer (ViscoQC 300, Anton Paar, Graz, Austria) at $25^{\circ} \mathrm{C}$. The average particle size in each case was examined using a particle size analyzer (LSTM 13320 MW, Beckman Coulter, Brea, CA, USA) and an image analyzer (ImageJ 1.53o, public domain software). The compressive strength was measured using a fixture with an Instron 4206 (Instron, Norwood, MA, USA) testing system. Specimens $20 \mathrm{~mm} \times 20 \mathrm{~mm} \times 20 \mathrm{~mm}$ in size were utilized at a crosshead rate of $0.5 \mathrm{~mm} / \mathrm{min}$.

\section{Results and Discussions}

\subsection{Preparation of Reticulated Porous Zirconia}

Polyurethane foam with pore densities of 25, 45, 60 and 80 PPI, as shown in Figure 1a, was used as a sacrificial polymer template. It was sintered at $1480{ }^{\circ} \mathrm{C}$ for $1 \mathrm{~h}$ to prepare the reticulated porous zirconia, as shown in Figure 1b. When manufacturing reticulated porous ceramics using the replica method, in order to obtain high compressive strength, it is important that the prepared ceramic slurry completely penetrates into the inside of the polymer template. For this reason, the rheological properties of ceramic slurry must be carefully considered when preparing reticulated porous ceramics. There are two considerations when optimizing the rheological properties of ceramic slurry. One is to adjust the properties of the raw materials, such as the particle size, shape, and fluidity of the ceramic powder, while the other is to control the type and content of any additives used, i.e., the binder, plasticizer, dispersant, and thickener, among others $[15,16]$.

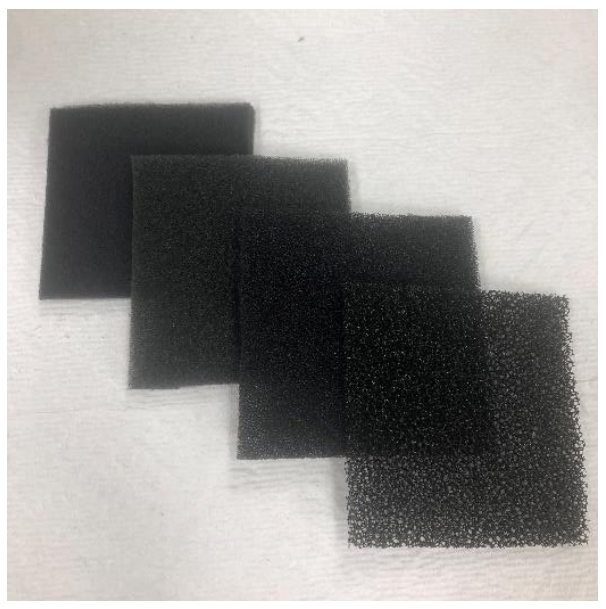

(a)

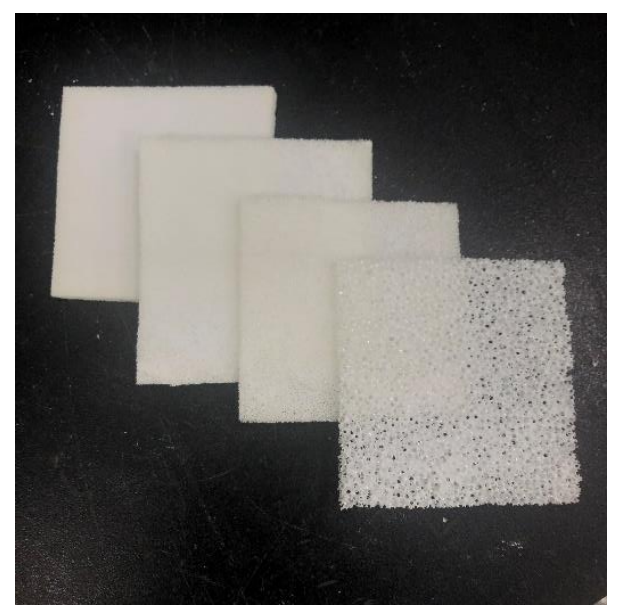

(b)

Figure 1. Optical images of (a) commercial polyurethane foam samples with pore densities of 80, 60, 45 , and 25 PPI (left to right, respectively), which were used as sacrificial polymer templates as part of the replica method, and (b) reticulated porous zirconia specimens with pore densities of 80,60, 45, and 25 PPI (left to right, respectively) sintered at $1480{ }^{\circ} \mathrm{C}$.

Initially, the authors considered the solid loading amount in the zirconia slurry. If the solid loading level in the ceramic slurry is not sufficient, the result can be a thin coating and poor densification. On the other hand, if the solid loading level of the ceramic slurry is too high, the outcome can be a thick coating and blocked pores. Therefore, the solid loading level in the ceramic slurry must be optimized properly to ensure a uniform coating. 
Figure 2a-c show the density, linear shrinkage, and compressive strength outcomes of reticulated porous zirconia specimens with different solid loading levels (75 150 wt.\%) in the zirconia slurry. With solid loading of $125 \mathrm{wt} . \%$, the density and compressive strength reached a peak, and when the solid loading level was $150 \mathrm{wt} . \%$, these values decreased. This can be explained as follows: logically, an increase in the solid loading level of the zirconia slurry can result in an increase in the viscosity. Accordingly, the density and compressive strength increase. However, when the solid loading level reaches $150 \mathrm{wt} . \%$, the viscosity is too high and the fluidity of the zirconia slurry drops, resulting in a non-uniform coating and eventually causing the compressive strength to decrease as well.

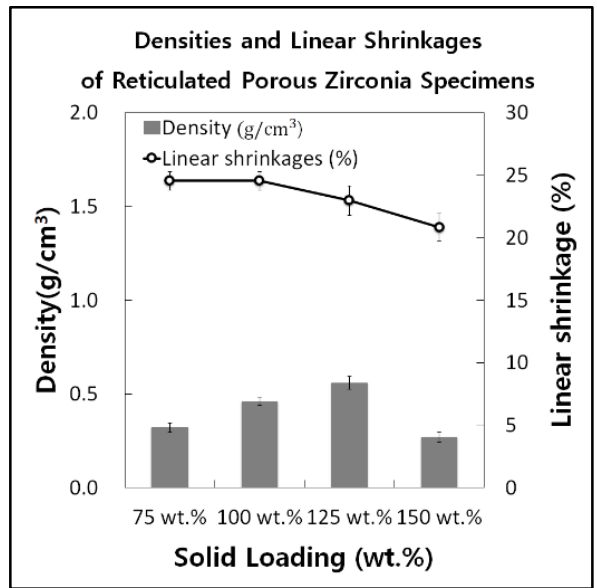

(a)

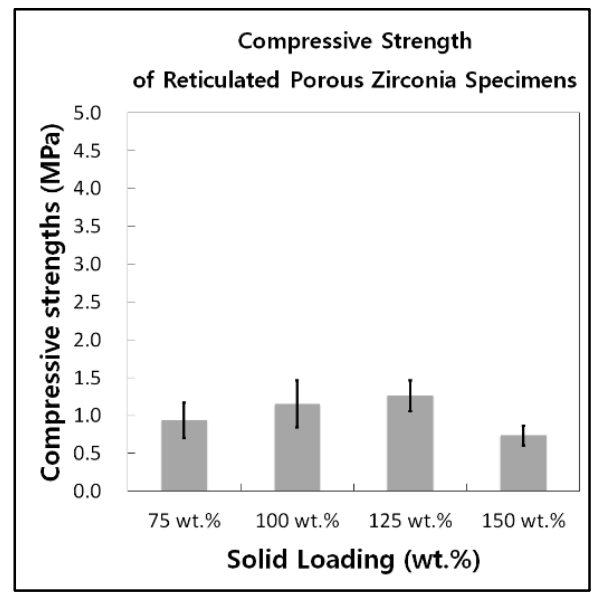

(b)

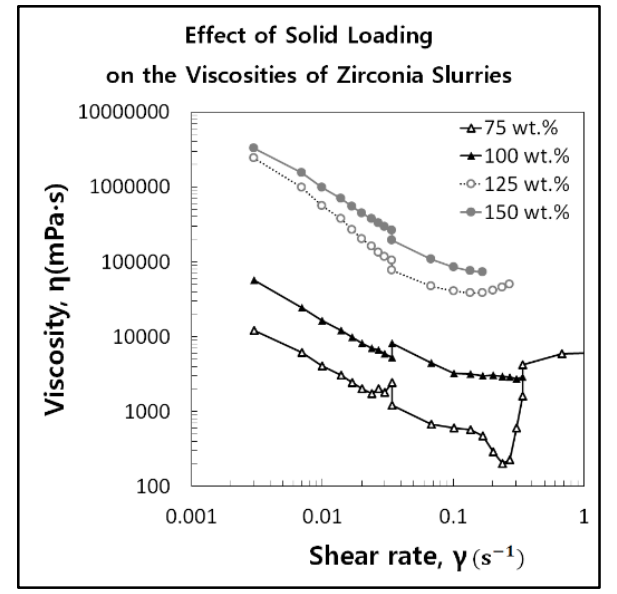

(c)

Figure 2. (a) Density and linear shrinkage outcomes, (b) compressive strength, and (c) viscosity values of reticulated porous zirconia specimens with different solid loading rates of 75-150 wt.\%.

The viscosity outcomes with different solid loading levels (75 150 wt.\%) in the zirconia slurry are shown in Figure 2c. As the solid loading level was increased, the viscosity of the zirconia slurry gradually increased, and when the solid loading level was $125 \mathrm{wt} . \%$, the increase in the viscosity was greatest. Although this condition has the highest density and compressive strength, the authors utilized a solid loading level of $100 \mathrm{wt} . \%$ in the ensuing experiment. The aim of this paper is to investigate the effects on the compressive strength of reticulated porous zirconia using diverse process conditions. Accordingly, the authors decided to conduct a follow-up experiment under these conditions because the result at $100 \mathrm{wt} . \%$ solid loading showed appropriate compressive strength and relatively low viscosity.

After fixing the solid loading level in the zirconia slurry to $100 \mathrm{wt} . \%$, the effects of a change in the average particle size on the characteristics of the reticulated porous zirconia 
were investigated. When the number of particles in the ceramic slurry is constant, the viscosity of the ceramic slurry increases as the particle size becomes finer. Therefore, the authors attempted to utilize the ball-milling process to create a finer size and observed the effects of the particle size. The microstructures of the zirconia particles obtained with different ball-milling times of $0,1,4,8$, and $24 \mathrm{~h}$ are shown in Figure 3 . The microstructure of the zirconia particles after ball-milling for $4 \mathrm{~h}$ shows an uneven particle distribution, but it was also noted that many particles approximately $0.5 \mu \mathrm{m}$ or less in size are distributed throughout the specimen. Furthermore, an examination of the zirconia particles ballmilled for $24 \mathrm{~h}$ showed that the particle distribution is uniform and consists of spherical particles. These results indicate that the cohesion of the primary particle size of the raw material was reduced and that more uniform zirconia powder can be prepared using the ball-milling process.

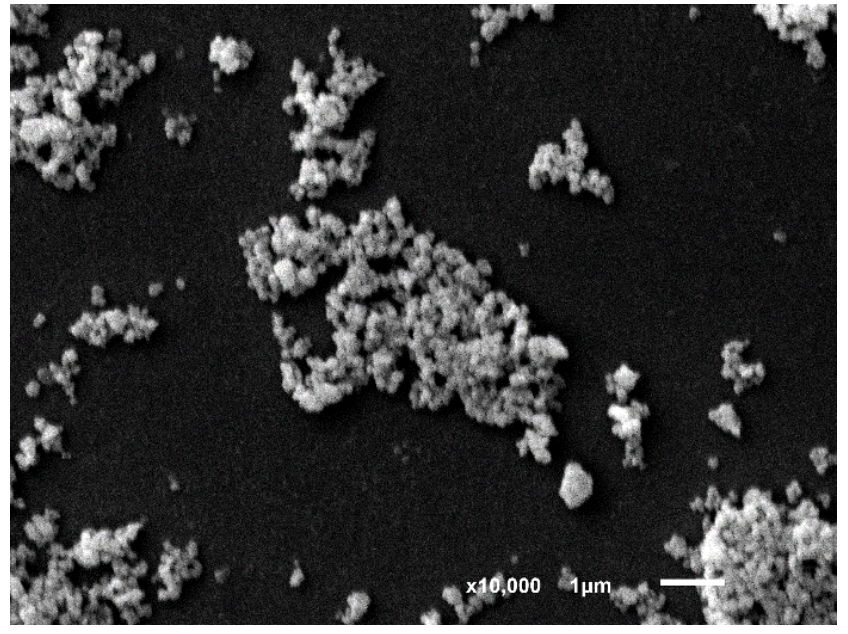

(a)

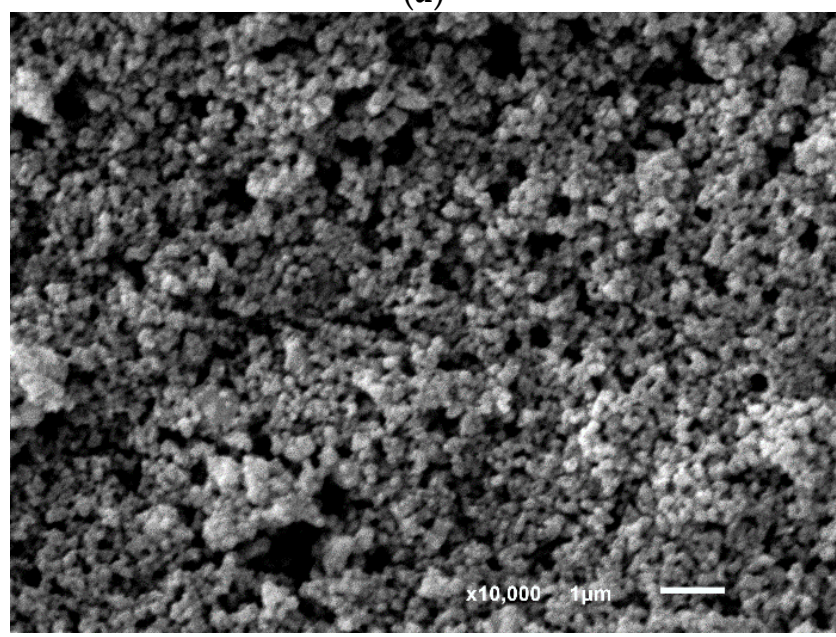

(c)

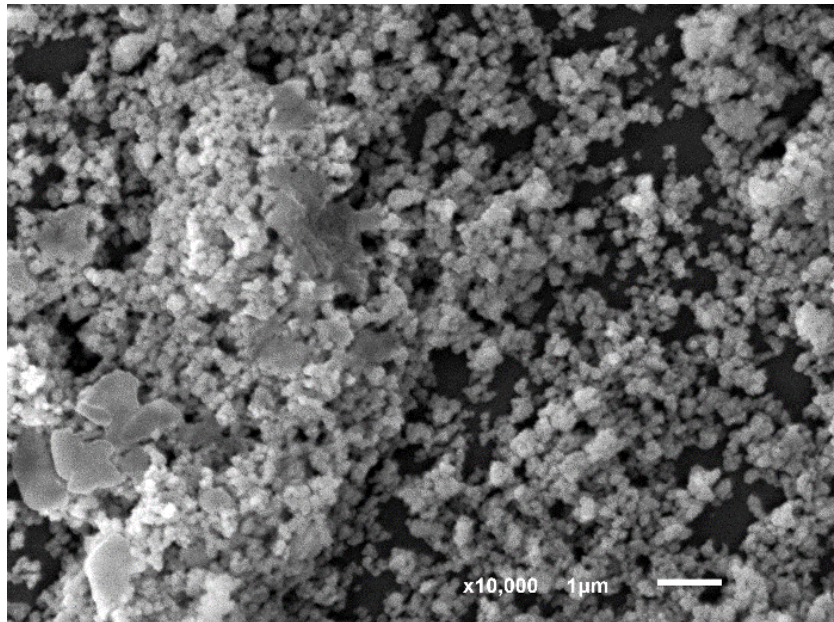

(b)

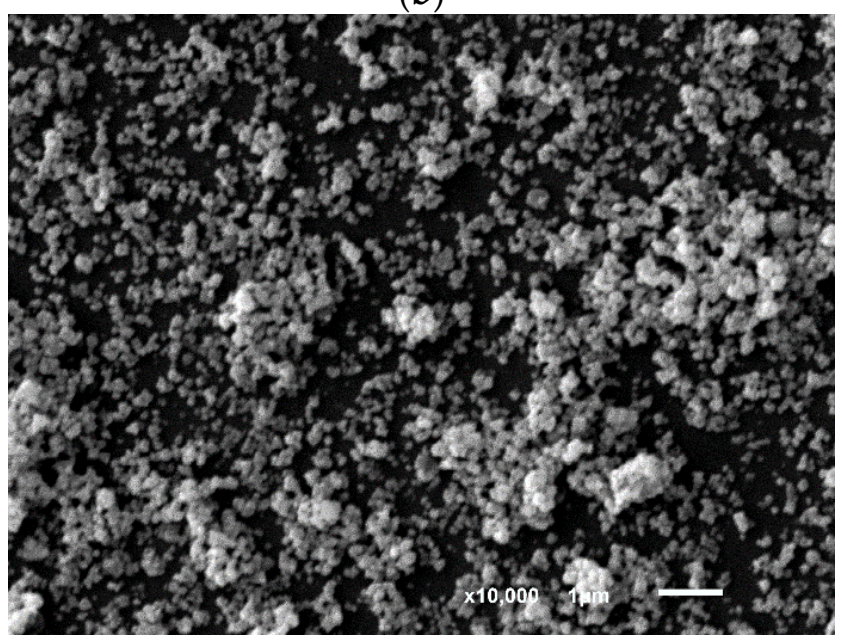

(d)

Figure 3. Cont. 


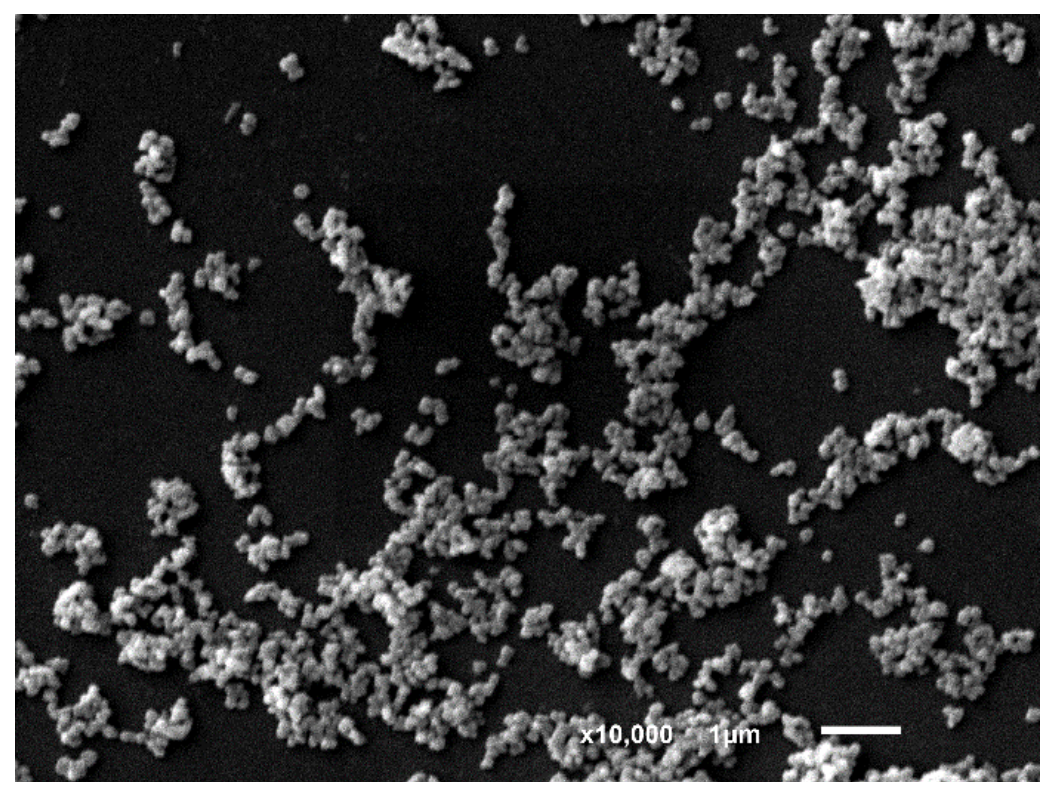

(e)

Figure 3. Scanning electron microscopy (SEM) images of zirconia particles ball-milled for (a) $0 \mathrm{~h}$ (as-received), (b) $1 \mathrm{~h}$ (coarse), (c) $4 \mathrm{~h}$ (intermediate), (d) $8 \mathrm{~h}$ (fine), and (e) $24 \mathrm{~h}$ (fine).

We used distilled water as a solvent for the particle size analysis, and an ultrasonic disperser was used to improve the dispersibility of the zirconia particles in the solution. The particle size distributions of zirconia are shown in Figure $4 \mathrm{a}$ and the median particle sizes of zirconia which were measured by laser particle size analysis and SEM image analysis are shown in Figure $4 \mathrm{~b}$. As expected from the microstructure observations, the median particle sizes of the zirconia decreased correspondingly in the order of $1.04,0.62,0.34,0.32$, and $0.2 \mu \mathrm{m}$ with an increase in the ball-milling time. Additionally, expected from the SEM images in Figure 3, the median particle size of zirconia measured by SEM image analysis is not precise. Therefore, it can be suggested that laser particle size analysis is efficient to track a slight change in mean particle size during the ball-milling process. When the ball-milling time was four hours, the greatest decrease in the particle size occurred, and when ball-milling time exceeded $24 \mathrm{~h}$, the particle size approached 0.2 to $0.3 \mu \mathrm{m}$. At this point, even if the ball-milling time was increased continuously, the particle size did not decrease further, Hence, it was judged that the formed particle size using the ball-milling process was limited. In order to investigate the effects of the reduced particle size, we initially measured the viscosity of the zirconia slurry. As shown in the results in Figure 4c, the viscosity of the zirconia slurry increased gradually as the ball-milling time increased. Typically, the viscosity of ceramic slurry is a well-known function of the concentration ratio and the particle size ratio of the total solid loading level. Thus, it is believed that the finer the particle size is, the higher the packing density of the particles in the ceramic slurry becomes, and the more liquid is absorbed into the pores between the particles. It is believed that more liquid moves effectively when flowing, resulting in relatively high viscosity. 


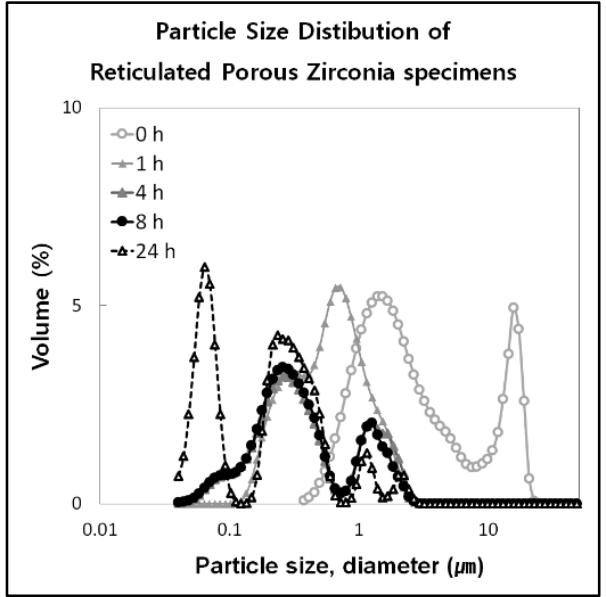

(a)

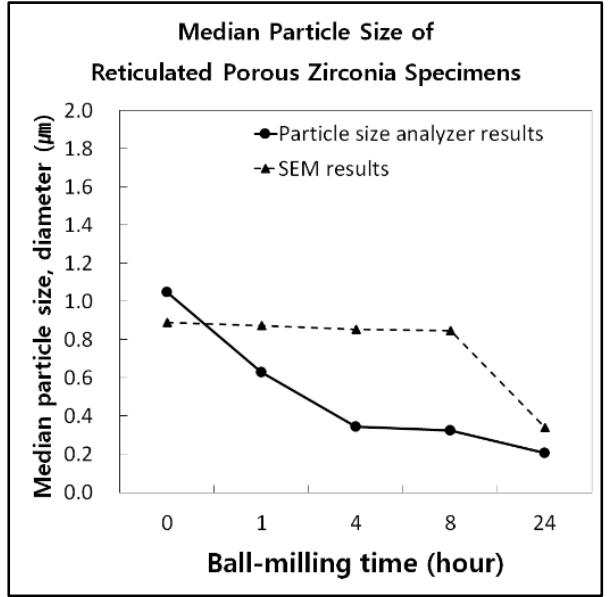

(b)

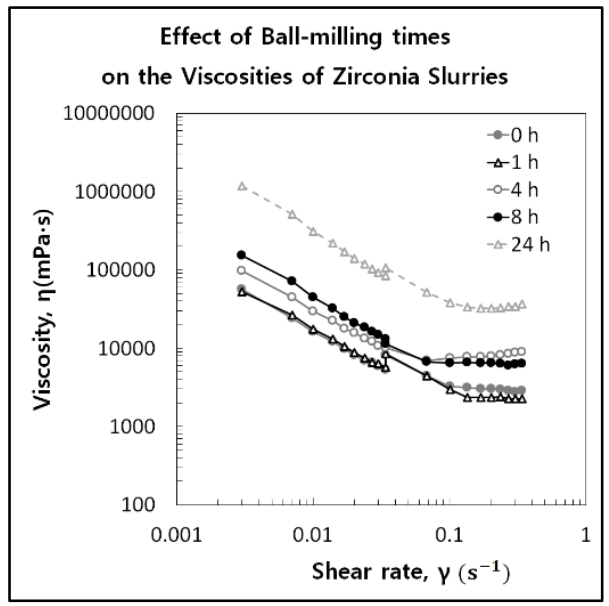

(c)

Figure 4. (a) Particle size distribution, (b) median particle size distributions and (c) viscosities of zirconia slurry samples ball-milled for $0,1,4,8$, and $24 \mathrm{~h}$.

We confirmed that the viscosity increased as the particle size was decreased. With this in mind, the densities and compressive strength were measured, as shown in Figure 5a. As the particle size of zirconia was decreased, the density and compressive strength of the reticulated porous zirconia clearly increased. However, sharp decreases were noted when ball-milling for more than $24 \mathrm{~h}$. This result is notable in that the highest density and compressive strength did not appear at the highest viscosity. What this result suggests is that the ceramic slurry, when created with a viscosity level past a certain point, deteriorates the density and compressive strength of reticulated porous zirconia. All things considered, the average particle size decreased after ball-milling for $24 \mathrm{~h}$ and the viscosity of the zirconia slurry increased above a critical point, indicating that a non-uniform coating could be formed. The pore size distributions of reticulated porous zirconia with a change in the particle size when ball-milled for $0,1,4,8$, and $24 \mathrm{~h}$ were observed, as shown in Figure $5 \mathrm{~b}$. For the reticulated porous zirconia using particles without the ball-milling process, the pore size was in the approximate range of 1 to $10 \mu \mathrm{m}$. However, for the reticulated porous zirconia prepared using zirconia ball-milled for more than $8 \mathrm{~h}$, a pore size distribution of 1 to $10 \mu \mathrm{m}$ was not observed. In this case, densification between the particles in the strut during the sintering process is likely to have arisen, resulting in the disappearance of pores in the range of 1 to $10 \mu \mathrm{m}$. 


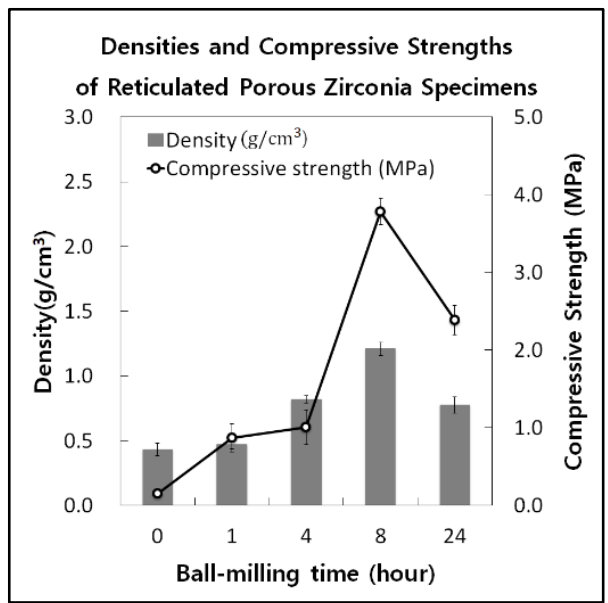

(a)

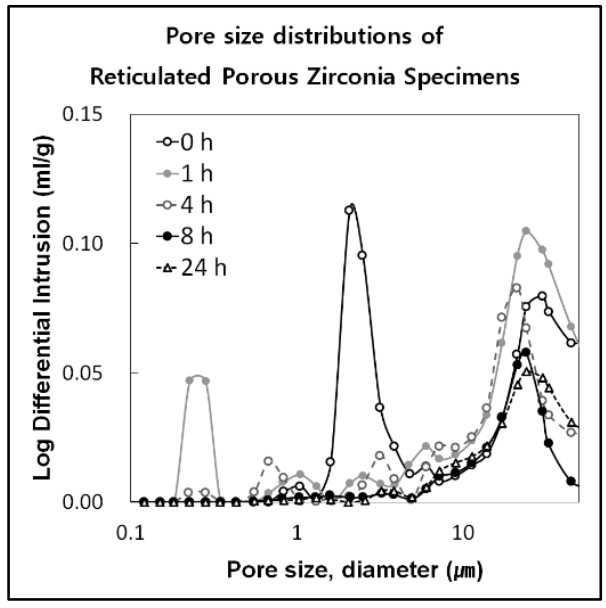

(b)

Figure 5. (a) Densities and compressive strength outcomes and (b) pore size distributions of reticulated porous zirconia specimen ball-milled for $0,1,4,8$, and $24 \mathrm{~h}$.

\subsection{Effects of Changes in the Types and Amounts of Binder and Diseprsants}

In the previous experimental results, reticulated porous zirconia with the highest compressive strength of $3.78 \mathrm{MPa}$ was prepared after ball-milling for eight hours. Therefore, the subsequent condition of the zirconia slurry used a fixed particle size with eight hours of ball-milling.

The second part of this study considered the optimization of additives in the zirconia slurry. Among the various types of additives in use at present, this study concentrated on the type and amount of a binder and a dispersant, which are known to affect the properties of ceramic slurries significantly. Normally, polyvinyl alcohol (PVA), which is often used as an organic binder in ceramic slurries, can cover on the surfaces of these particles to increase the bonding strength between the particles and improve the fluidity. However, because it is removed during heat treatment, when an excessive amount is added, voids may form between the particles, reducing the compressive strength after sintering [17]. Therefore, when PVA is used as an organic binder, optimizing the amount of PVA in the ceramic slurry is important. Figure 6a shows the viscosity of zirconia slurries prepared with $0 \sim 1.5 \mathrm{wt} . \%$ PVA. As the amount of added PVA in the zirconia slurry increases, the viscosity of the zirconia slurry increases. The density and compressive strength with different amounts from 0 to $1.5 \mathrm{wt} . \%$ PVA are shown in Figure $6 \mathrm{~b}$. When the added amount of PVA is $1 \mathrm{wt} . \%$, the compressive strength of the reticulated porous zirconia is approximately $3.86 \mathrm{MPa}$. In contrast, the density of the reticulated porous zirconia remained constant even when the amount of added PVA increased. This result indicates that an increase in the amount of added PVA does not cause an increase in the applied mass, but it was judged that it had the effect of improving the densification by narrowing the distance between the particles. However, when the amount of added PVA was $1 \mathrm{wt} . \%$ or more, the compressive strength decreased. This result indicates that high viscosity due to an excessive addition of PVA results in poor compressive strength. Therefore, in this study, the amount of PVA in the zirconia slurry was fixed at $1 \mathrm{wt} . \%$. The pore size distributions of reticulated porous zirconia specimens with changes in the amount of PVA are shown in Figure 6c. Regardless of the increase in the amount of added PVA, the pore size remained uniformly distributed, whereas the log differential intrusions were slightly decreased. These results indicate that the distance between the particles is narrowed, which is believed to have affected the densification. 


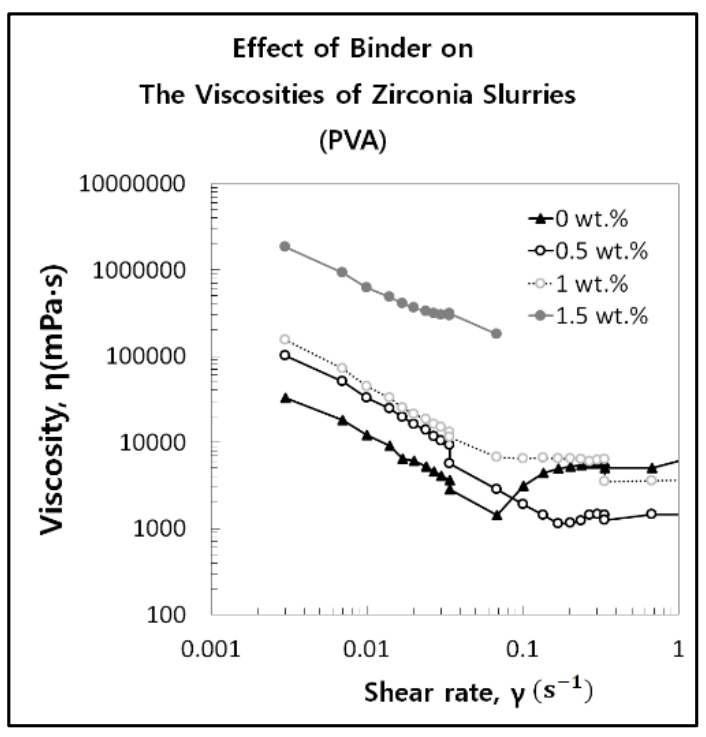

(a)

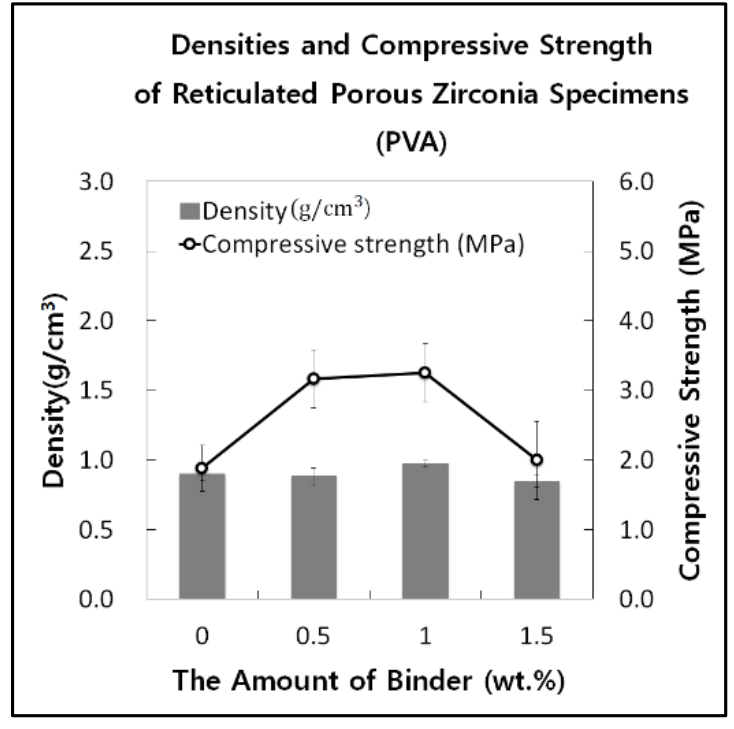

(b)

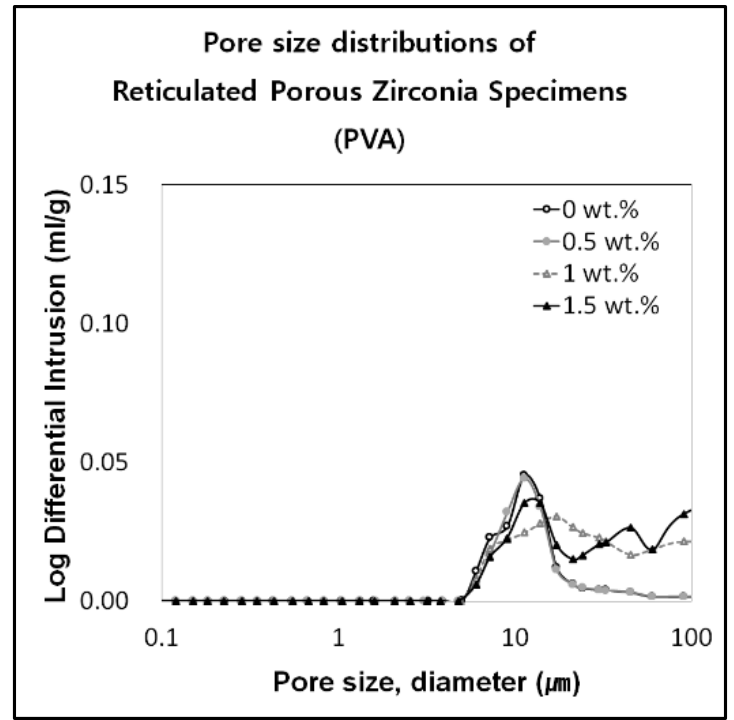

(c)

Figure 6. Effects of the addition of a binder (0-1.5 wt.\% PVA) on the (a) viscosities, (b) densities and compressive strength, and the (c) pore size distribution of reticulated porous zirconia specimens.

The authors realized that the particle size can affect the viscosity of the zirconia slurry and that the viscosity should be at a certain level in order to improve the compressive strength. However, as the particle size decreases, agglomeration between the particles and the formation of sediment upon standing appear. These outcomes stem from an increase in the specific surface area. These can degrade the compressive strength by forming an uneven coating during the impregnation step. Therefore, the dispersion properties in the ceramic slurry may be a key factor when attempting to improve the compressive strength. In this study, the zirconia slurry is optimized with two types of dispersants: DARVAN C-N and Dolapix CE 64.

DARVAN C-N, an ammonium polymethacrylate solution, is completely soluble in water systems and is commonly applied in the electronics and in specific ceramics fields [18]. It produces slurries with exceptionally low viscosity levels without being prone to foaming. Dolapix CE 64, a carbonic-acid-based polyelectrolyte solution, is also dispersed in water and used in alumina [19], zirconia [20], and cordierite-based-glass ceramics [21]. Each 
dispersant was added in the range of $0-1.5 \mathrm{wt} . \%$ to determine the optimal amount in the zirconia slurry. Figure 7a shows the viscosity of the zirconia slurries prepared with 0-1.5 wt.\% DARVAN C-N. Particles in the zirconia slurry are dispersed by electric repulsive force by adding DARVAN C-N; thus, as the amount of DARVAN C-N is increased, the viscosity of the zirconia slurry decreases gradually. However, because the distance between the dispersed particles at the same volume is limited, the viscosity did not decrease further, even when an amount of $1.5 \mathrm{wt} . \%$ of DARVAN C-N or more was added. The density and compressive strength of the reticulated porous zirconia specimens with different amounts of DARVAN C-N are shown in Figure 7b. In comparison, the density and compressive strength decreased as the amount of DARVAN C-N was increased. These results indicate a decrease in the viscosity in the zirconia slurry upon the addition of DARVAN C-N as a dispersant, with no effect on or increase in the compressive strength. The pore size distributions of the reticulated porous zirconia specimens upon the addition of DARVAN C-N are shown in Figure 7c. Regardless of the amount of DARVAN C-N, it is believed that the pore size distribution ranged from approximately 10 to $100 \mu \mathrm{m}$.

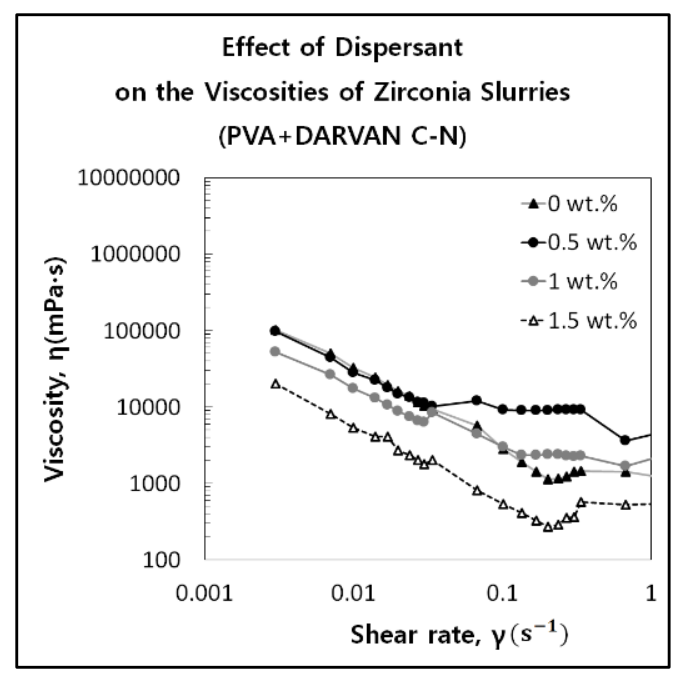

(a)

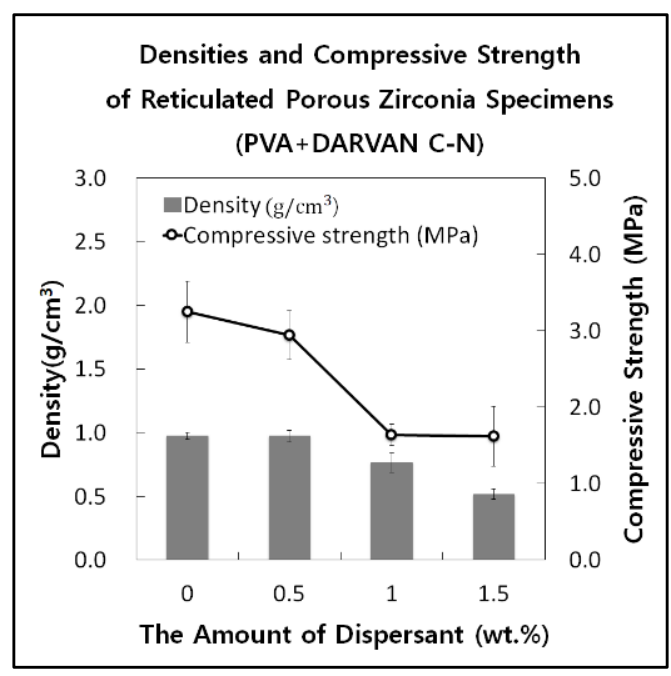

(b)

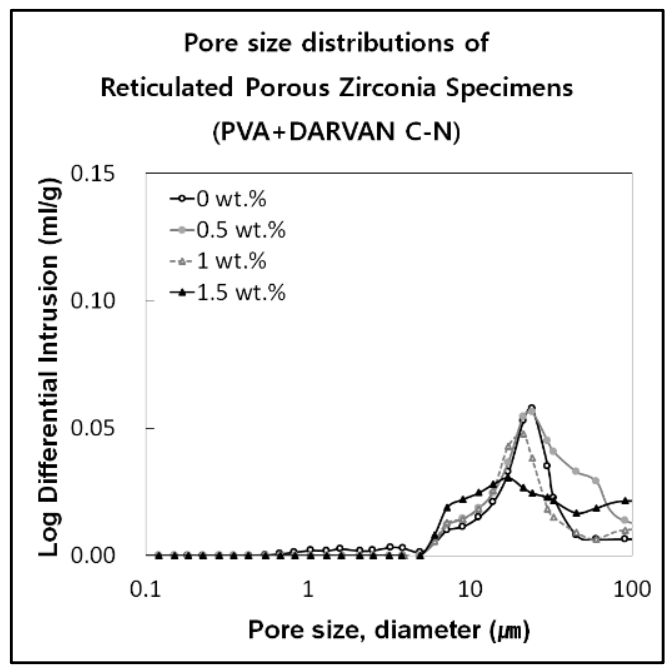

(c)

Figure 7. Effects of the addition of a dispersant (0-1.5 wt.\% DARVAN C-N) on the (a) viscosities, (b) densities and compressive strength outcomes, and the (c) pore size distributions of reticulated porous zirconia specimens. 
To compare the dispersion effect, the authors conducted a study of Dolapix CE 64, which has also been studied in the literature [20]. Figure 8a shows the viscosity of the zirconia slurries prepared with 0 1.5 wt.\% of Dolapix CE 64. As the amount of Dolapix CE 64 increased, the viscosity of the zirconia slurry gradually decreased; these results are similar to the results for DARVAN C-N. The density and compressive strength with different amounts of Dolapix CE 64 are shown in Figure 8b. An important aspect here is that a different outcome arose when DARVAN C-N was used. As the amount of Dolapix CE 64 increased, the density remained constant but the compressive strength peaked at $1 \mathrm{wt} . \%$ of Dolapix CE 64 In this case, the density makes it difficult to predict the compressive strength. Therefore, the viscosity and pore properties should be analyzed at the same time. The pore size distributions with 0 1.5 wt.\% of Dolapix CE 64 are shown in Figure 8c. When 1 wt.\% of Dolapix CE 64 was added, the pore size decreased slightly, indicating that the pore size decreased and the compressive strength increased when preparing reticulated porous zirconia with few macro voids of the strut walls under the optimized dispersant condition (in this study, $1 \mathrm{wt} . \%$ Dolapix CE 64). When the dispersant was $1.5 \mathrm{wt} . \%$ Dolapix CE 64 , the pore size was similar to when $1 \mathrm{wt} . \%$ Dolapix CE 64 was used, but the density and compressive strength decreased. This result indicates that the viscosity of the zirconia slurry increased again without full penetration into the polymer template, leading to simultaneous reductions in the density and compressive strength.

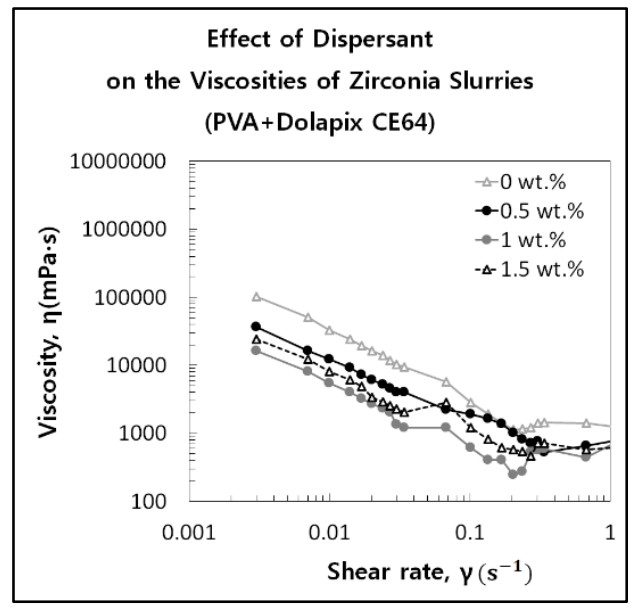

(a)

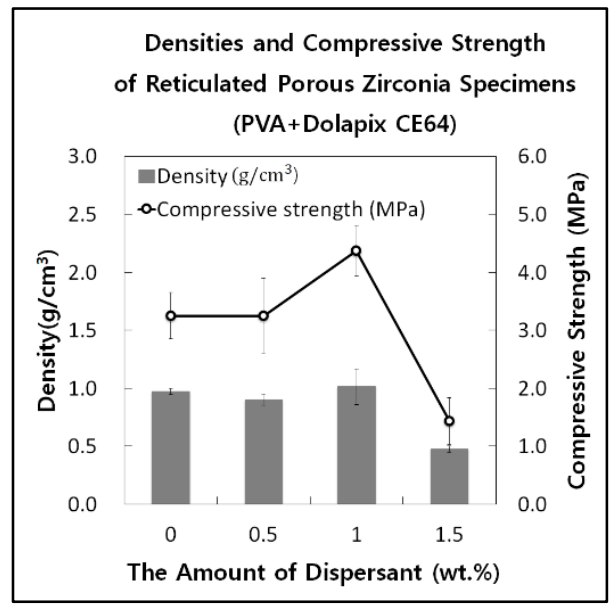

(b)

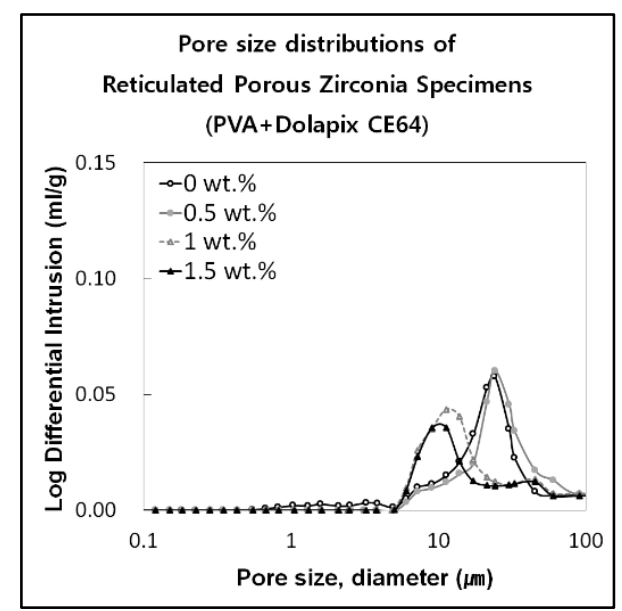

(c)

Figure 8. Effects of the addition of a dispersant (0-1.5wt.\% Dolapix CE 64) on the (a) viscosities, (b) densities and compressive strength outcomes, and the (c) pore size distributions of reticulated porous zirconia specimens. 
Additionally, it was inferred that the addition of Dolapix CE 64 had a stronger effect of dispersing the particles in the zirconia slurry compared to when DARVAN C-N was added. When a dispersant was not added to the zirconia slurry, the viscosity was 101,400 m.Pas at a shear rate of 0.003 . However, when $1 \mathrm{wt} . \%$ of DARVAN C-N was added, the viscosity decreased to $52,740 \mathrm{~m} \cdot$ Pas at a shear rate of 0.003 , while when $1 \mathrm{wt} . \%$ of Dolapix CE 64 was added, the viscosity decreased to $16,230 \mathrm{~m} \cdot$ Pas at a shear rate of 0.003 . It can be concluded that this is relatively more effective for the zirconia slurry because the viscosity was lowered by more six times at the same shear rate when adding $1 \mathrm{wt} . \%$ of Dolapix CE 64 . Nonetheless, when $1.5 \mathrm{wt} . \%$ of Dolapix CE 64 is added, the viscosity increased again to $24,340 \mathrm{~m} \cdot$ Pas at a shear rate of 0.003 . According to these results, when a dispersant is added to zirconia slurry, the viscosity is lowered, but it increases at a certain point. Thus, we find that when Dolapix CE 64 was added as a dispersant at $1 \mathrm{wt} . \%$, the best condition arises to create reticulated porous zirconia with excellent compressive strength. However, we cannot be sure that this can be applied to all types of ceramics. For now, we only can be certain that optimization of the dispersant is necessary.

\subsection{Effects of Multiple Slurry Coatings on Reticulated Porous Zirconia}

Thus far, this study has focused on the effects on the compressive strength when changing the properties of the ceramic slurry. In another method, the authors investigated whether multiple slurry coatings could effectively improve the compressive strength. There are several methods that can be used to improve the compressive strength of reticulated porous ceramics, such as vacuum infiltration (reticulated porous mullite) [22], centrifugation coating [23], slurry rheology modification (reticulated porous alumina) [24], and multiple slurry coatings (reticulated porous silicon carbide [9]). Among these methods, there has been little discussion of multiple slurry coatings. The authors admit that this method is inefficient economically, but it is worth studying at this point to expand the field of research.

Three slurry coatings were used, and sintering was performed every time. Figure $9 \mathrm{a}$ shows the density and compressive strength of the reticulated porous zirconia specimens according to number of coatings, which ranged here from one to three. As the number of slurry coatings increases, the compressive strength of the reticulated porous zirconia is more than doubled from 4.37 to $9.43 \mathrm{MPa}$. One study concentrated on reticulated porous alumina with multiple slurry coatings applied. In that study, the compressive strength for a single coating was $0.07 \mathrm{MPa}$, and that after a triple coating it was $0.2 \mathrm{MPa}$ [25]. This data showed a pore density of $10 \mathrm{PPI}$ with sintering at $1400{ }^{\circ} \mathrm{C}$. Although both the pore density and the sintering temperature were different in each case, it was noted that reticulated porous zirconia could more effectively enhance the compressive strength when using multiple slurry coatings as opposed to reticulated porous alumina.

The pore size distributions of specimens with multiple slurry coatings are shown in Figure $9 \mathrm{~b}$. Regardless of the number of coatings, the results indicate the highest number of pores in the range of approximately 10 to $100 \mu \mathrm{m}$.

The log differential intrusion is also slightly decreased as the number of coatings increases. These results can be explained by examining the microstructure in Figure 10. The fractured strut microstructures of reticulated porous zirconia with (a) one coating, (b) two coatings, and (c) three coatings are shown in Figure 10. When coated once, fractured strut walls of reticulated porous zirconia formed thin triangular voids. These voids can significantly affect the compressive strength because the sample becomes brittle. When coated twice, the fractured strut walls of reticulated porous zirconia formed thick triangular voids, and when coated thrice, the internal voids were completely filled. It can be judged that these microstructures coincide with the results in Figure 9b, showing a decrease in the $\log$ differential intrusion outcome. 


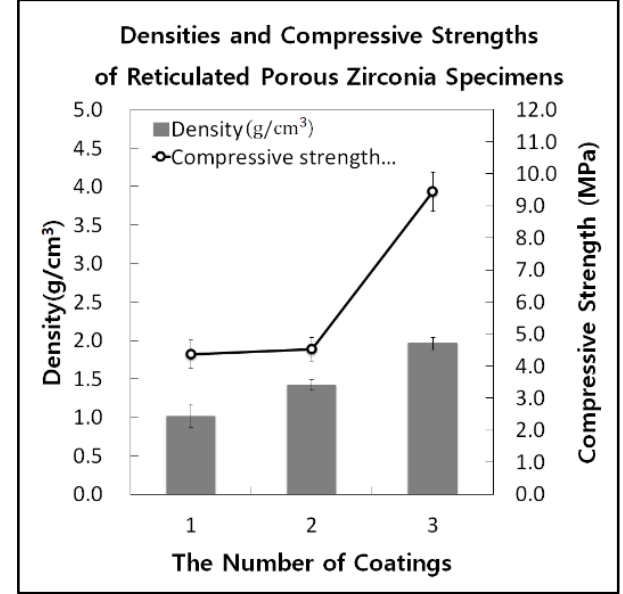

(a)

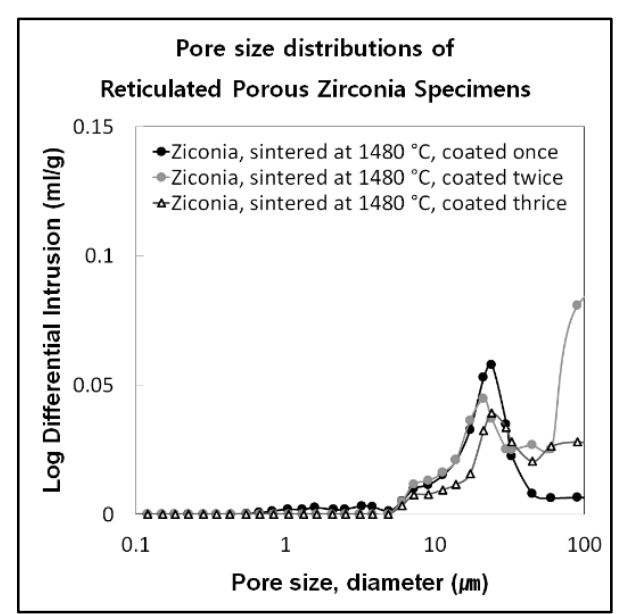

(b)

Figure 9. (a) Densities and compressive strength outcomes, and (b) pore size distributions when increasing the number of coatings of reticulated porous zirconia.

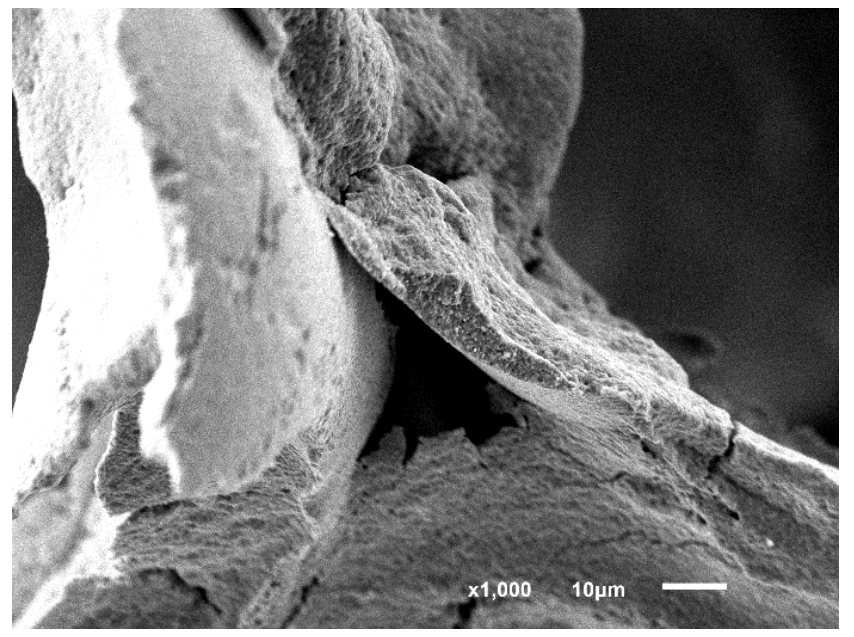

(a)

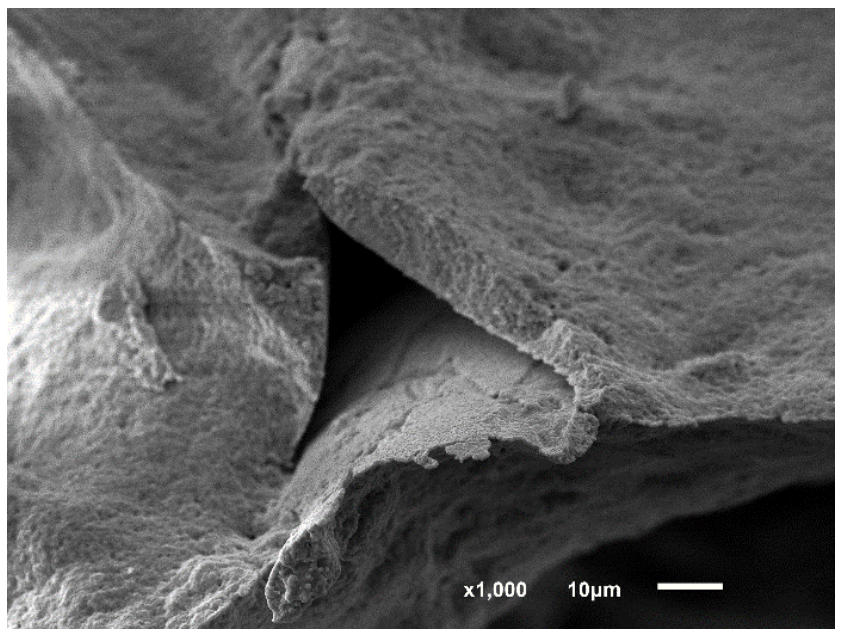

(b)

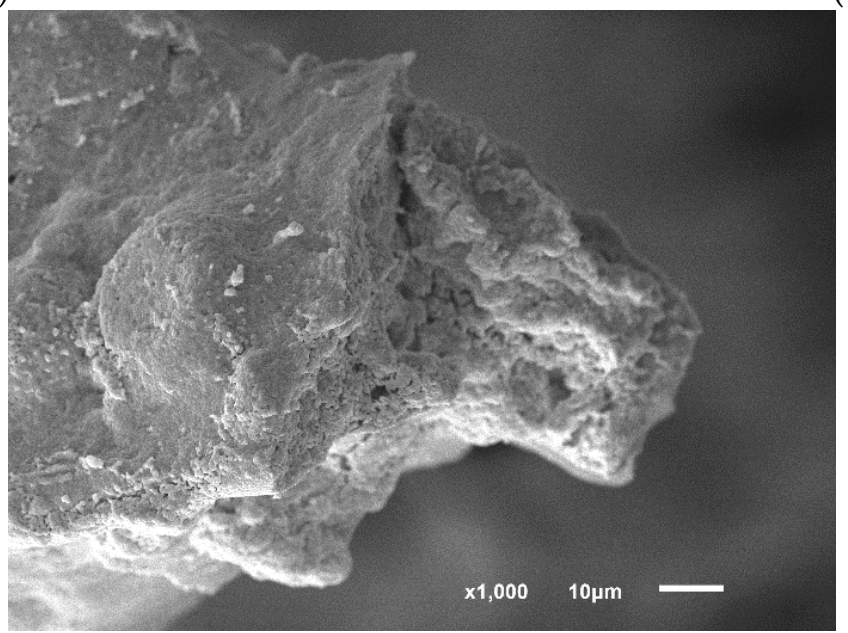

(c)

Figure 10. SEM image of (a) a fractured strut wall of reticulated porous coated with zirconia once, (b) thick reticulated porous coated with zirconia twice, and (c) a filled strut wall of reticulated porous coated with zirconia three times. 
In Figure 11a, at a pore density of $45 \mathrm{PPI}$, the three-dimensional microstructure of the reticulated porous zirconia reconstructed by $\mu-\mathrm{CT}$ is shown. A typical cross-section of the $\mu-\mathrm{CT}$ reconstruction is shown in Figure $11 \mathrm{~b}$. The $\mu-\mathrm{CT}$ image indicates that the reticulated porous zirconia has highly interconnected pore channels. Macro voids, which may be caused by non-optimized process conditions, are not shown in Figure 11.

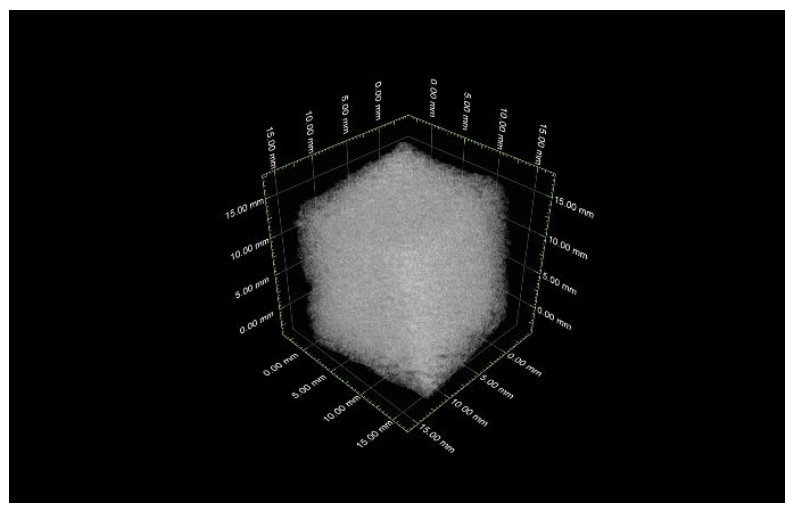

(a)

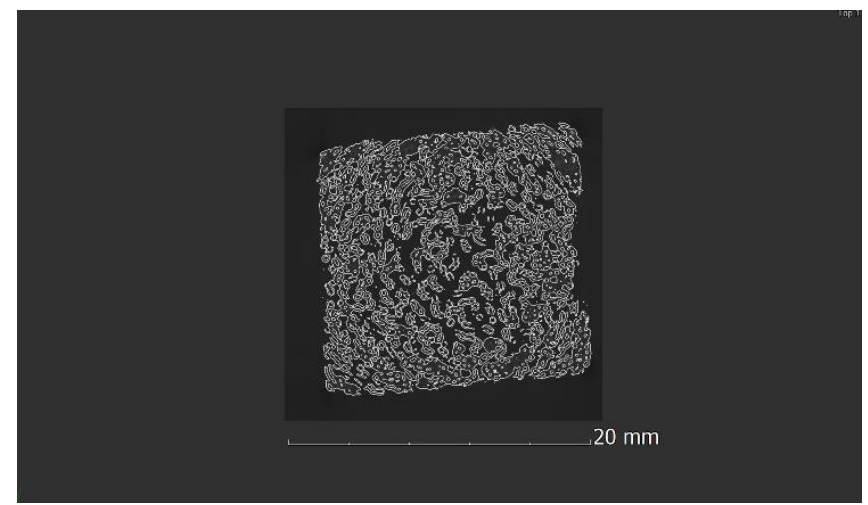

(b)

Figure 11. (a) A typical three-dimensional microstructure of reticulated porous zirconia at 45 PPI prepared under optimized processing conditions and reconstructed by $\mu-C T$. (b) Representative slice extracted to show the corresponding $\mu$-CT reconstructions with a porosity level of 45 PPI.

In Figure 12, at pore densities of 45, 60, and 80 PPI, the dielectric breakdown strength outcomes of the reticulated porous diatomite-kaolin composite sintered at $1200{ }^{\circ} \mathrm{C}$ [26], the reticulated porous alumina sintered at $1600{ }^{\circ} \mathrm{C}$ and the reticulated porous zirconia sintered at $1480{ }^{\circ} \mathrm{C}$ are shown, respectively. To the best of the authors' knowledge, few works have examined the dielectric breakdown strength capabilities of reticulated porous ceramic materials. This topic is difficult to explore because high porosity can decrease the dielectric breakdown strength [27]. The dielectric breakdown strength capabilities of porous ceramics such as porous alumina (porosity $<10 \%, 11.8 \mathrm{kV} / \mathrm{mm}$ ) [28], porous yttria stabilized zirconia (porosity < 5\%, 1.86-2.08 MV/cm) [29], and porous lead zirconate titanate (porosity < 10\%, $6.3 \mathrm{kV} / \mathrm{mm}$ ) have been investigated under low-porosity conditions. However, for a proper understanding of the effect of high porosity on the dielectric breakdown strength, it is necessary to measure specimens with high porosity. The dielectric breakdown strengths of the reticulated porous zirconia ranged from approximately 10 to $15 \mathrm{kV} / \mathrm{cm}$, regardless of the pore density. Measurements at a pore density of less than 45 PPI were difficult because these specimens were prone to arc generation; thus, the results were not obtained. However, the results in this paper are shown to be excellent when considering the high porosity. Additionally, these results are similar to those in previous studies of reticulated porous alumina and reticulated porous diatomite-kaolin composites, indicating that reticulated porous zirconia is lightweight and has excellent compressive strength while also having adequate dielectric breakdown strength, enabling a wide range of industrial applications, such as dielectric materials. 


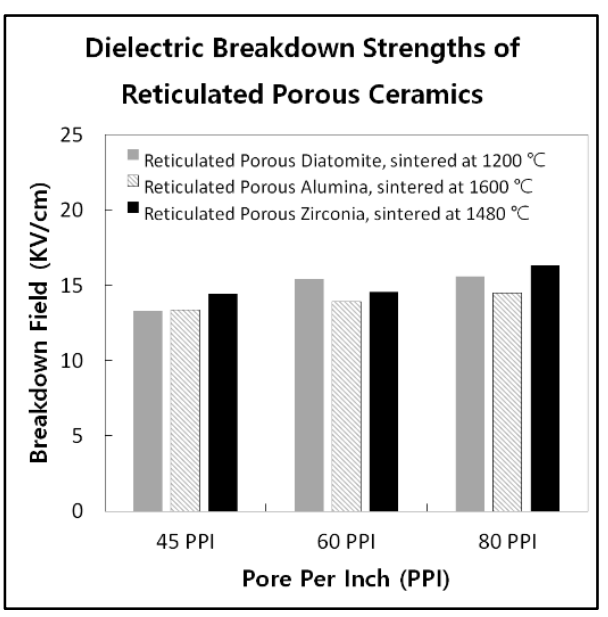

Figure 12. Dielectric breakdown strengths of reticulated porous diatomite-kaolin reticulated porous alumina and reticulated porous zirconia specimens with pore densities of 45, 60, and 80 PPI.

In summary, in a previous study, the authors manufactured reticulated porous zirconia which was sintered at $1600^{\circ} \mathrm{C}$ at $45 \mathrm{PPI}$, with compressive strength of about 1.26 MP [30]. However, the authors determined that this compressive strength result was insufficient compared to the results of the other types of porous zirconia, such as porous yttria-stabilized zirconia [30,31], fibrous zirconia [32], and ultra-high-porosity zirconia [33], among others. It is necessary to study how to improve the compressive strength of reticulated porous zirconia to expand the application of these materials. This study focused on improving the compressive strength of reticulated porous zirconia by optimizing various process conditions, specifically the particle size, solid loading level, and types of additives. First, the optimal particle size was determined by varying the ball-milling time, and the effect on the compressive strength was observed. When reticulated porous zirconia was ball-milled for $0,1,4$, and $8 \mathrm{~h}$ and sintered at $1480{ }^{\circ} \mathrm{C}$ with $45 \mathrm{PPI}$, the corresponding compressive strength outcomes increased to approximately $0.14,0.87,1.00$, and $3.78 \mathrm{MPa}$.

These results depict the effects of a reduction in the particle size as the ball-milling time increased. As the particle size decreases, the specific surface area increases, indicating an increase in the sintering driving force; it has been reported that the particle size is linked to improved compressive strength of the final sintered body [34]. However, if the particle size is reduced to the nano-sized range, this result will be affected by different sintering mechanisms. Therefore, we can at least determine that the compressive strength of the reticulated porous zirconia prepared by the replica method could be increased by a reduction in the particle size in the micro-scale range.

When reticulated porous zirconia was ball-milled for $24 \mathrm{~h}$ and sintered at $1480{ }^{\circ} \mathrm{C}$ at $45 \mathrm{PPI}$, the compressive strength dropped to $2.38 \mathrm{MPa}$. This result was judged as meaning that as the ball-milling time increased, the average particle size continued to decrease, and thus the viscosity of the zirconia slurry increased. Through these results, it can be concluded that when the viscosity of zirconia slurry increases beyond a certain range, it becomes a factor for reducing the compressive strength.

Secondly, the types and amounts of additives (binders and dispersants) were investigated to optimize the viscosity of the zirconia slurry. When $1 \mathrm{wt} . \%$ PVA is added as a binder and $1 \mathrm{wt} . \%$ Dolapix CE 64 is added as a dispersant, the compressive strength of reticulated porous zirconia reaches approximately $4.37 \mathrm{MPa}$. The results mean that optimizing process conditions is the simplest, cheapest, and most effective method.

Lastly, reticulated porous zirconia can be utilized in multiple slurry coatings to achieve a further increase in the compressive strength. In this study, we applied multiple slurry coatings ranging from one to three. With an increase in the number of slurry coatings, the triangular voids in the struts were filled and thickened, with compressive strength increasing from 4.37 to $9.43 \mathrm{MPa}$. 


\section{Conclusions}

The optimal particle size was determined by varying the ball-milling time, and the effect on the compressive strength was observed. We can suggest that the compressive strength of the reticulated porous zirconia prepared by the replica method could be increased by a reduction in the particle size in the micro-scale range. Additionally, it can be concluded that when the viscosity of zirconia slurry increases beyond a certain range, it becomes a factor for reducing the compressive strength.

Additionally, the types and amounts of additives (binders and dispersants) were investigated to optimize the viscosity of the zirconia slurry. With the results, it can be suggested that optimizing process conditions is the simplest, cheapest, and most effective method.

Additionally, reticulated porous zirconia can be utilized in multiple slurry coatings to achieve a further increase in the compressive strength. All of the above-mentioned changes in various process conditions were beneficial to improve the compressive strength of reticulated porous zirconia.

Author Contributions: J.-H.H. and S.-H.K. conceived and designed the experiments; S.L. and C.-Y.L. performed the experiments; J.L. and J.-H.H. analyzed the data; I.-H.S. contributed reagents/materials/analysis tools; S.L. wrote the paper. All authors have read and agreed to the published version of the manuscript.

Funding: This research was funded by Fundamental Research Program of the Korean Institute of Materials Science (KIMS), Grant No. PNK8120, and by National R\&D Program through the National Research Foundation of Korea (NRF) funded by Ministry of Science and ICT (2020M3H4A3106359).

Acknowledgments: This research was funded by the Fundamental Research Program of the Korean Institute of Materials Science (KIMS), Grant No. PNK8120, and by National R\&D Program through the National Research Foundation of Korea (NRF) funded by Ministry of Science and ICT (2020M3H4A3106359).

Conflicts of Interest: The authors declare no conflict of interest.

\section{References}

1. Zhou, W.; Ai, S.; Chen, M.; Zhang, R.; He, R.; Pei, Y.; Fang, D. Preparation and thermodynamic analysis of the porous $\mathrm{ZrO}_{2} /\left(\mathrm{ZrO}_{2}+\mathrm{Ni}\right)$ functionally graded bolted joint. Composites Part B: Engineering 2015, 82, 13-22. [CrossRef]

2. Zhou, W.; Zhang, R.; Fang, D. Design and analysis of the porous $\mathrm{ZrO}_{2} /\left(\mathrm{ZrO}_{2}+\mathrm{Ni}\right)$ ceramic joint with load bearing-heat insulation integration. Ceram. Int. 2016, 42, 1416-1424. [CrossRef]

3. Zhou, W.; Zhang, R.; Ai, S.; He, R.; Pei, Y.; Fang, D. Load distribution in threads of porous metal-ceramic functionally graded composite joints subjected to thermomechanical loading. Compos. Struct. 2015, 134, 680-688. [CrossRef]

4. Nanjangud, S.C.; Brezny, R.; Green, D.J. Strength and Young's Modulus Behavior of a Partially Sintered Porous Alumina. J. Am. Ceram. Soc. 1995, 78, 266-268. [CrossRef]

5. Fey, T.; Betke, U.; Rannabauer, S.; Scheffler, M. Reticulated Replica Ceramic Foams: Processing, Functionalization, and Characterization. Adv. Eng. Mater. 2017, 19, 1700369-1700383. [CrossRef]

6. Gain, A.K.; Song, H.-Y.; Lee, B.-T. Microstructure and mechanical properties of porous yttria stabilized zirconia ceramic using poly methyl methacrylate powder. Scripta Mater. 2006, 54, 2081-2085. [CrossRef]

7. Huo, W.-L.; Zhang, X.-Y.; Chen, Y.-G.; Lu, Y.-J.; Liu, W.-T.; Xi, X.-Q.; Wang, Y.-L.; Xu, J.; Yang, J.-L.; Gauckler, L. Highly Porous Zirconia Ceramic Foams with Low Thermal Conductivity from Particle-Stabilized Foams. J. Am. Ceram. Soc. 2016, 99, 3512-3515. [CrossRef]

8. Banerjee, A.; Bala Chandran, R.; Davidson, J.H. Experimental investigation of a reticulated porous alumina heat exchanger for high temperature gas heat recovery. Appl. Therm. Eng. 2015, 75, 889-895. [CrossRef]

9. Liang, X.; Li, Y.; Liu, J.; Sang, S.; Chen, Y.; Li, B.; Aneziris, C.G. Improvement of the mechanical properties of SiC reticulated porous ceramics with optimized three-layered struts for porous media combustion. Ceram. Int. 2017, 43, 3741-3747. [CrossRef]

10. Chen, R.; Jia, W.; Shan, Q.; Ling, Y.; Lao, D.; Wang, Y.; Li, S.; Hei, D. A novel design of Al2O3-ZrO2 reticulated porous ceramics with hierarchical pore structures and excellent properties. J. Eur. Ceram. Soc. 2019, 39, 1877-1886. [CrossRef]

11. Maccauro, C.P. Zirconia as a ceramic biomaterial. Biomaterials 1999, 20, 1-25.

12. Gautam, C.; Joyner, J.; Gautam, A.; Rao, J.; Vajtai, R. Zirconia based dental ceramics: Structure, mechanical properties, biocompatibility and applications. Dalton Trans 2016, 45, 19194-19215. [CrossRef] [PubMed]

13. Kondoh, J.; Shiota, H.; Kawachi, K.; Nakatani, T. Yttria concentration dependence of tensile strength in yttria-stabilized zirconia. J. Alloys Compd. 2004, 365, 253-258. [CrossRef] 
14. Jun, I.-K.; Koh, Y.-H.; Song, J.-H.; Lee, S.-H.; Kim, H.-E. Improved compressive strength of reticulated porous zirconia using carbon coated polymeric sponge as novel template. Mater. Lett. 2006, 60, 2507-2510. [CrossRef]

15. Tsetsekou, A.; Agrafiotis, C.; Milias, A. Optimization of the rheological properties of alumina slurries for ceramic processing applications Part I: Slip-casting. J. Eur. Ceram. Soc. 2011, 21, 363-373. [CrossRef]

16. Liu, W.; Jin, L.; Wang, S. Preparation of transparent Y2O3 ceramic via gel casting: Realization of high solid volume via surface modification. J. Am. Ceram. Soc. 2019, 102, 6414-6421. [CrossRef]

17. Baklouti, S.; Bouaziz, J.; Chartier, T.; Baumard, J.F. Binder burnout and evolution of the mechanical strengthof dry-pressed ceramics containing poly(vinyl alcohol). J. Eur. Ceram. Soc. 2001, 21, 1087-1092. [CrossRef]

18. Singh, B.P.; Bhattacharjee, S.; Besra, L.; Sengupta, D.K. Evaluation of dispersibility of aqueous alumina suspension in presence of Darvan C. Ceram. Int. 2004, 30, 939-946. [CrossRef]

19. Gaydardzhiev, S.; Ay, P. Characterisation of aqueous suspensions of fumed aluminium oxide in presence of two Dolapix dispersants. J. Mater. Sci. 2006, 41, 5257-5262. [CrossRef]

20. Rao, S.P.; Tripathy, S.S.; Raichur, A.M. Dispersion studies of sub-micron zirconia using Dolapix CE 64. Colloids Surf. A Physicochem. Eng. Asp. 2007, 302, 553-558. [CrossRef]

21. Mei, S.; Yang, J.; Ferreira, J.M. Comparison of dispersants performance in slip casting of cordierite-based glass-ceramics. Ceram. Int. 2003, 29, 785-791. [CrossRef]

22. Liang, X.; Li, Y.; Pan, L.; Sang, S.; Zhu, T.; Li, B.; Aneziris, C.G. Preparation and enhancement of mullite reticulated porous ceramics for porous media combustion. Ceram. Int. 2019, 45, 22226-22232. [CrossRef]

23. Pu, X.; Liu, X.; Qiu, F.; Huang, L. Novel Method To Optimize the Structure of Reticulated Porous Ceramics. J. Am. Ceram. Soc. 2005, 87, 1392-1394. [CrossRef]

24. Voigt, C.; Aneziris, C.G.; Hubálková, J.; Franks, G. Rheological Characterization of Slurries for the Preparation of Alumina Foams via Replica Technique. J. Am. Ceram. Soc. 2015, 98, 1460-1463. [CrossRef]

25. Ha, J.-H.; Lee, S.; Choi, J.R.; Lee, J.; Song, I.-H.; Chung, T.-J. A cobalt-coated reticulated porous alumina for radar-absorption applications. J. Aust. Ceram. Soc. 2019, 55, 883-891. [CrossRef]

26. Lee, S.; Ha, J.-H.; Lee, J.; Song, I.-H.; Kwon, S.-H. Preparation and Characterization of a Low-Cost and Natural Material-Based Reticulated Porous Diatomite-Kaolin Composite. Appl. Sci. 2020, 10, 2125. [CrossRef]

27. Praveenkumar, B.; Kumar, H.H.; Kharat, D.K. Characterization and microstructure of porous lead zirconate titanate ceramics. Bull. Mater. Sci. 2005, 28, 453-455. [CrossRef]

28. Zhang, T.; Lei, Y.; Yin, J.; Du, J.; Yu, P. Effects of pores on dielectric breakdown of alumina ceramics under AC electric field. Ceram. Int. 2019, 45, 13951-13957. [CrossRef]

29. Jongprateep, O.; Petrovsky, V.; Dogan, F. Effects of Yttria Concentration and Microstructure on Electric Breakdown of Yttria Stabilized Zirconia. J. Met. Mater. Miner. 2008, 18, 9-14.

30. Lee, C.-Y.; Lee, S.; Ha, J.-H.; Lee, J.; Song, I.-H.; Moon, K.-S. Effect of the Sintering Temperature on the Compressive Strengths of Reticulated Porous Zirconia. Appl. Sci. 2021, 11, 5672. [CrossRef]

31. Zhou, J.; Wang, C.-A.; Colombo, P. Porous yttria-Stabilized Zirconia Ceramics Fabricated by Nonaqueous-Based Gelcasting Process with PMMA Microsphere as Pore-Forming Agent. J. Am. Ceram. Soc. 2013, 96, 266-271. [CrossRef]

32. Sun, J.; Hu, Z.; Li, J.; Zhang, H.; Sun, C. Thermal and mechanical properties of fibrous zirconia ceramics with ultra-high porosity. Ceram. Int. 2014, 40, 11787-11793. [CrossRef]

33. Hong, C.; Zhang, X.; Han, J.; Du, J.; Han, W. Ultra-high-porosity zirconia ceramics fabricated by novel room-temperature freeze-casting. Scripta Mater. 2009, 60, 563-566. [CrossRef]

34. Rahimian, M.; Ehsani, N.; Parvin, N.; Baharvandi, H.r. The effect of particle size, sintering temperature and sintering time on the properties of $\mathrm{Al}-\mathrm{Al}_{2} \mathrm{O}_{3}$ composites, made by powder metallurgy. J. Mater. Process. Technol. 2009, 209, 5387-5393. [CrossRef] 